\title{
Clinical Presentation and Response to Therapy in Children with Cutaneous Leishmaniasis
}

\author{
Carvel Suprien, ${ }^{1}$ Paulo N. Rocha,,${ }^{1,2}$ Marina Teixeira, ${ }^{3}$ Lucas P. Carvalho, $, 2,4,5,6$ Luiz H. Guimarães, ${ }^{6,7}$ Toby Bonvoisin, ${ }^{8}$ \\ Paulo R. L. Machado, ${ }^{2,6}$ and Edgar M. Carvalho ${ }^{2,5,6 *}$ \\ ${ }^{1}$ Programa de Pós-Graduação em Ciências da Saúde da Faculdade de Medicina da Universidade Federal da Bahia, Salvador, Brazil; ${ }^{2}$ Serviço de \\ Imunologia do Complexo Hospitalar Universitário Professor Edgard Santos, Universidade Federal da Bahia, Salvador, Brazil; ${ }^{3}$ University of \\ Massachusetts Boston, Boston, Massachusetts; ${ }^{4}$ Instituto de Ciências da Saúde da Universidade Federal da Bahia, Salvador, Brazil; ${ }^{5}$ Instituto \\ Gonçalo Moniz (IGM), FIOCRUZ-BA, Salvador, Brazil; ${ }^{6}$ National Institutes of Science and Technology in Tropical Diseases, Ministry of Science and \\ Technology, Salvador, Brazil; ${ }^{7}$ Universidade Federal do Sul da Bahia, Ilhéus, Brazil; ${ }^{8}$ The University of Sheffield, Sheffield, England
}

\begin{abstract}
Cutaneous leishmaniasis (CL) caused by Leishmania braziliensis occurs predominantly in adult males. Herein, we compare the clinical presentation and the response to antimony therapy of CL in children versus adults. Participants included 571 patients with CL; of these, 129 were children (age $\leq 12$ years). Cure was defined as the complete healing of ulcer in the absence of raised borders at day 90 after initiation of therapy. Failure was defined by the presence of an active ulcer or a scar with elevated borders at day 90 . In comparison with adults, children had shorter duration of illness, more lesions in the head, and smaller ulcers. Risk factors for therapeutic failure were younger age, shorter duration of disease, higher number of lesions, and larger size of the biggest ulcer. When age was categorized in $\leq 12$-year-olds (children versus adults), it predicted therapeutic failure with statistical significance at day 60 but not at day 90 . In conclusion, our data indicate that there are significant differences in the clinical presentation of CL between children and adults. Physicians caring for children with CL should be aware that lesions may take longer to heal and remain alert for the possibility of higher odds of therapeutic failure in this group.
\end{abstract}

\section{INTRODUCTION}

Leishmaniasis is a spectrum of diseases caused by parasites from the genus Leishmania. It presents different clinical forms, depending on the species of the Leishmania involved and parasite and host factors. ${ }^{1}$ In the world, there are approximately 1.5 million of new cases of cutaneous leishmaniasis (CL) every year. ${ }^{2}$ In Brazil, there are close to 30,000 new cases reported annually, and the incidence is estimated at 14.7 cases per 100,000 people. $^{3}$ The three main species that cause CL in Brazil are Leishmania (Viannia) braziliensis, Leishmania (Viannia) guyanensis, and Leishmania (Viannia) amazonensis, which are transmitted through sand flies of the Lutzomyia genus. ${ }^{4}$ Cutaneous leishmaniasis occurs predominantly in young male adults; however, because of changes in ecology and epidemiology, the disease has been more frequently observed in children and the elderly. ${ }^{5-7}$

The clinical presentation of $C L$ is a well-limited ulcerated lesion with raised borders predominantly in the inferior limbs. ${ }^{8}$ However, the disease can present with ulcers in any area of the body and with multiple lesions. Atypical presentation with verrucous, nodular, or large ulcerated lesions has been observed mainly in the adult population, in pregnant women and in patients coinfected with HIV. ${ }^{9-11}$ Moreover, there is an emergent form of $L$. braziliensis infection called disseminated leishmaniasis characterized by more than 10 and up to thousands of acneiform papular and ulcerated lesions in more than two parts of the body. ${ }^{7,12,13}$

The recommended therapy for $\mathrm{CL}$ in Brazil is meglumine antimoniate administered by intravenous or intramuscular route in the dose of $20 \mathrm{mg} / \mathrm{kg} /$ weight for 20 days with a maximum daily dose of $1,200 \mathrm{mg}^{3,14}$ The cure rate varies according to species and geographic region., ${ }^{4,15,16}$ In the village of Corte de Pedra, one of the most important areas of L. braziliensis transmission in Latin American, while about

*Address correspondence to Edgar M. Carvalho, Instituto Gonçalo Moniz (FIOCRUZ-BA), Rua Waldemar Falcão, 121, Candeal, Salvador 40296-710, Brazil. E-mail: imuno@ufba.br
30 years ago, the cure rate of antimony for CL was $95 \%,{ }^{17,18}$ and in the last 15 years, the cure rate ranged from $45 \%$ to $53 \% .^{16,19,20}$ Moreover, in Colombia, success with this drug can be as low as $25 \%$ in children younger than 5 years. ${ }^{21}$ There are only a few studies about CL in children; in one of them, the response to therapy was found to be worse in children than in adults, especially if children were 8 years old or younger. ${ }^{22}$ Furthermore, it was demonstrated that children have lower levels of meglumine antimoniate in comparison to adults, when the drug is administered at the same dosage per kilogram, ${ }^{23}$ as well as lower levels of miltefosine. ${ }^{22}$ The aim of the present study was to compare the clinical presentation and the response to treatment with meglumine antimoniate in children and adults with CL.

\section{METHODS}

Patients and study area. In 2016, a total of 871 patients sought medical care at the Health Post of Corte de Pedra, a reference center for the diagnosis and therapy of tegumentary leishmaniasis. The sample selection is shown in Figure 1. After excluding patients because of other diagnosis rather than $\mathrm{CL}$, lack of follow-up, treatment with other drugs, and incomplete data, 571 patients were considered eligible for the study.

The age, gender, duration of illness, size of lesions, number and location of the lesions on the body, and response to therapy were registered (Figure 1). Patients were initially subdivided into three different groups according to their age at the moment of entry at the clinic. The groups assigned were as follows: between 0 and 12 years old, $\geq 13 \leq 18$ years old, and older than 18 years. The role of age in response to therapy was then further explored by categorizing patients into two groups: $0-12$ years old and $\geq 13$ years old. Age was also used as a continuous and a categorical (using 12 year old as the cutoff) independent variable in logistic regression analyses. The diagnosis was made in the presence of a typical ulcer of $C L$ associated with at least one of the following: 1) identification of L. braziliensis DNA through polymerase chain reaction (PCR) 


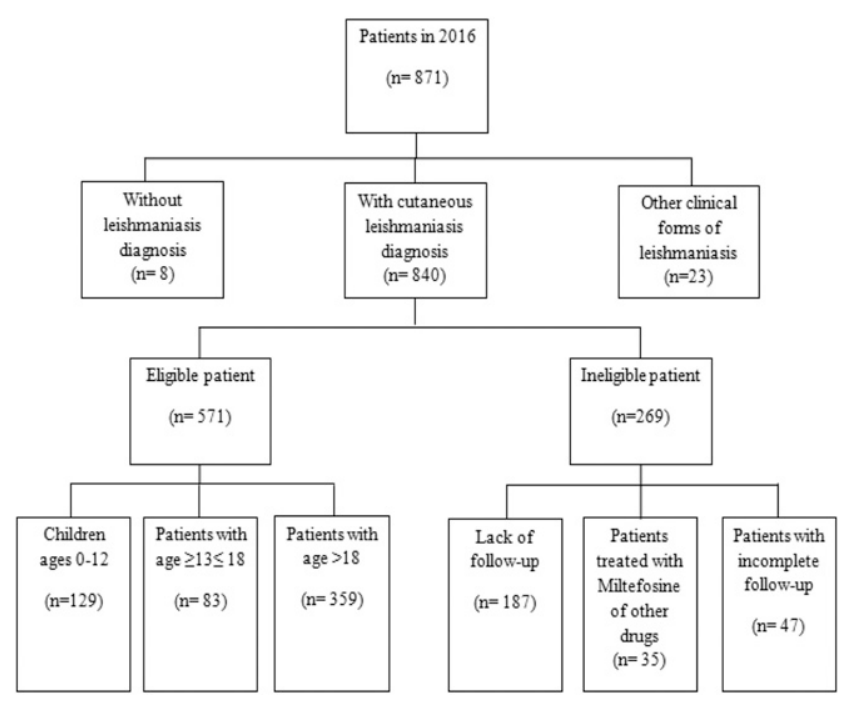

FIGURE 1. Flowchart with sample selection.

of the tissue of cutaneous ulcer obtained by biopsy, 2) identification of amastigotes in histopathologic studies, and 3) a positive leishmanin skin test performed with soluble Leishmania antigen, as previously described. ${ }^{24}$ All patients were treated with intravenous meglumine antimoniate, Glucantime (Sanofi-Aventis, Gentilly, France), with daily doses of 20 mg/ $\mathrm{kg}$ for 20 days. The criterion for cure was the complete healing of the ulcer in the absence of elevated borders at day 90 of treatment. Therapeutic failure was defined as the persistence of an active ulcer at day 90 or by the presence of a scar with raised borders.

Statistical analysis. Continuous data were summarized by mean $\pm S D$, and comparisons between two and three groups were made using the Student's $t$-test and one-way analysis of variance (ANOVA), respectively; multiple comparisons were performed using Bonferroni's post hoc test. Categorical data were summarized by absolute and relative frequencies and comparisons between groups were made with the chi-square test. All statistical analyses were performed with the Statistical Package for the Social Sciences software version 20.0 (IBM Inc., Chicago, IL). To identify predictors of therapeutic failure, we conducted univariate and multivariate logistic regression analyses. The significance level was defined as $P<0.05$.

Ethical issues. The Institutional Review Board of the Federal University of Bahia approved this study, and patients or their guardians were required to sign an informed consent form.

\section{RESULTS}

We studied 571 patients, aged $28.5 \pm 19.1$ years (range 0-99 years). The demographic features, clinical manifestations, and response to therapy on day 60 and day 90 in $C L$ patients stratified into three different age-groups are shown in Table 1.

There was a predominance of male patients in all groups but in particular in the age-group from 13 to 18 years. From the perspective of the clinical presentation, there was no difference between the groups regarding the number of lesions. The duration of the disease was shorter in children and teenagers than in adults, and the presence of lesions on the face or head was around four times higher in children than in adults. The size of the lesion in the children was smaller than in the other two groups $(P=0.002)$. There was no statistically significant difference in regard to response to treatment at day 60 or 90 after initiation of treatment.

The adherence to treatment (data not shown), age, duration of the disease, multiple lesions, and size of the lesion have been identified as factors associated with failure to therapy. ${ }^{25-27}$ To identify predictors of therapeutic failure in our study, we compared several demographical and clinical variables between two groups: those cured at day 90 and those who failed therapy (Table 2).

We did not detect an association between therapeutic failure and gender, weight, and location of the lesion. There was an association between therapeutic failure with younger patients, shorter duration of lesion, and occurrence of multiple lesions.

TABLE 1

Demographical, laboratorial, and clinical features of cutaneous leishmaniasis in children, adolescents, and adults

\begin{tabular}{|c|c|c|c|c|}
\hline Variable & $0-12$ years $(n=129)$ & $13-18$ years $(n=83)$ & $>18$ years $(n=359)$ & $P$-value \\
\hline Males & 71/129 (58.5\%) & $58 / 83(69.8 \%)$ & 200/359 (57.8\%) & 0.05 \\
\hline \multicolumn{5}{|l|}{ Duration of the disease } \\
\hline Within 30 days & 101/129 (78\%) & 65/83 (78\%) & 243/359 (68\%) & \multirow[t]{2}{*}{0.03} \\
\hline More than 30 days & $28 / 129$ (22\%) & $18 / 83(22 \%)$ & $116 / 359(32 \%)$ & \\
\hline \multicolumn{5}{|l|}{ Location of the largest lesion } \\
\hline Cephalic segment & $20 / 129(16 \%)$ & $4 / 83(5 \%)$ & $14 / 359(4 \%)$ & \multirow[t]{4}{*}{0.001} \\
\hline Chest and abdomen & $10 / 129(8 \%)$ & 7/83 (8\%) & $38 / 359$ (11\%) & \\
\hline Superior extremities & $16 / 129(12 \%)$ & $11 / 83(13 \%)$ & $44 / 359(12 \%)$ & \\
\hline Inferior extremities & $83 / 129(64 \%)$ & $61 / 83(74 \%)$ & 263/359 (73\%) & \\
\hline \multicolumn{5}{|l|}{ Number of lesions } \\
\hline Single lesion & $94 / 129(73 \%)$ & $54 / 83(65 \%)$ & 253/359 (71\%) & \multirow[t]{2}{*}{0.47} \\
\hline More than one lesion & $35 / 129(27 \%)$ & 29/83 (35\%) & 106/359 (30\%) & \\
\hline Largest diameter (mm) & $11.9 \pm 9.4$ & $16.6 \pm 9.9$ & $15.8 \pm 12.2$ & 0.002 \\
\hline Positive LST & 124/126 (98\%) & 81/83 (97\%) & 339/351 (96\%) & na \\
\hline $\begin{array}{l}\text { Presence of amastigotes in } \\
\text { histopathology }\end{array}$ & $0 / 1$ & $2 / 2(100 \%)$ & 11/13 (84\%) & na \\
\hline Positive PCR & $4 / 5(80 \%)$ & 20/22 (91\%) & $182 / 206(88 \%)$ & na \\
\hline Cure in 60 days & $22 / 129(17 \%)$ & $23 / 83(28 \%)$ & $90 / 359(25 \%)$ & 0.12 \\
\hline Cure in 90 days & $56 / 129(43 \%)$ & $33 / 83(40 \%)$ & $172 / 359(48 \%)$ & 0.34 \\
\hline
\end{tabular}

LST = Leishmania skin test; na = not applicable. The percentage may not add to $100 \%$ because of rounding. The categorical variables were compared using the $\mathrm{X}^{2}$ test, and the continuous variables by the ANOVA test. The $P$-value in the last column corresponds to the comparison between the three groups. Multiple comparisons of the continuous variables were performed using the post hoc test of Bonferroni. For the variable "largest diameter," two comparisons were statistically significant: $0-12$ vs. $12-18(P=0.011) ; 0-12$ vs. $>18(P=0.003)$; there was no difference between the age-groups $13-18$ vs. $>18$ years $(P=1.0)$. 
TABLE 2

Predictors of treatment failure in cutaneous leishmaniasis patients on day 90

\begin{tabular}{|c|c|c|c|}
\hline Variables & Cure $(n=261)$ & Failure $(n=310)$ & $P$-value \\
\hline Age (years), mean \pm SD & $31.5 \pm 20.6$ & $26.0 \pm 17.4$ & 0.001 \\
\hline Males & 144/261 (55\%) & $185 / 310(60 \%)$ & 0.317 \\
\hline Weight $(\mathrm{kg})$, mean $\pm \mathrm{SD}$ & $53.7 \pm 20.1$ & $55.6 \pm 22.5$ & 0.311 \\
\hline Duration of the disease (days), mean $\pm S D$ & $39.3 \pm 33.0$ & $32.0 \pm 22.4$ & 0.002 \\
\hline Within 30 days & $117 / 261(68 \%)$ & $232 / 310(75 \%)$ & 0.078 \\
\hline More than 30 days & $84 / 261(32 \%)$ & $78 / 310(25 \%)$ & \\
\hline \multicolumn{4}{|l|}{ Location of the biggest lesion } \\
\hline Cephalic segment & 18/261 (7\%) & 20/310 (7\%) & 0.246 \\
\hline Body & $30 / 261(12 \%)$ & 25/310 (8\%) & \\
\hline Upper extremities & 26/261 (10\%) & $45 / 310(15 \%)$ & \\
\hline Lower extremities & $187 / 261(72 \%)$ & $220 / 310(71 \%)$ & \\
\hline Number of lesions, mean \pm SD & $1.45 \pm 1.09$ & $1.65 \pm 1.21$ & 0.032 \\
\hline \multicolumn{4}{|l|}{ Number of lesions } \\
\hline Single lesion & 198/261 (76\%) & $203 / 310(66 \%)$ & 0.009 \\
\hline More than one lesion & $63 / 261(24 \%)$ & $107 / 310(35 \%)$ & \\
\hline $\begin{array}{l}\text { Diameter of the biggest lesion }(\mathrm{mm}) \\
\text { mean } \pm \text { SD }\end{array}$ & $13.4 \pm 8.8$ & $16.4 \pm 13.1$ & 0.001 \\
\hline
\end{tabular}
the Student's $t$-test.

To further explore the association between age and therapeutic failure, we conducted multivariate logistic regression analyses. Given their association with therapeutic failure in univariate analysis, the variables age, duration of the disease, number of lesions, and diameter of the biggest lesion were included in the multivariate models. Age was used as a continuous variable, and we found a statistically significant inverse association between younger age and therapeutic failure at 60 and 90 days (Table 3 ).

All four variables tested were independent predictors of therapeutic failure at 90 days. The age and duration of the disease have inverse association with therapeutic failure: the greater the age and duration of the disease, the smaller the chance of failure. For each additional year of age, the probability of treatment failure reduces by $1.7 \%$. For each extra day of duration of the disease, the chance of failure reduces by $1.3 \%$. The number of lesions and the diameter of the lesion were directly related with failure. For each extra lesion, the chance of failure increased by $17.6 \%$, and for each extra $\mathrm{mm}$ in the diameter of the lesion, the chance of failure increases by $3.6 \%$.

\section{DISCUSSION}

The aim of this study was to characterize the clinic presentation of $\mathrm{CL}$ in children and to compare response to treatment between children and adults with $\mathrm{CL}$ treated with meglumine antimoniate. The study took place in the village of Corte de Pedra, one of the most important endemic areas of L. braziliensis transmission in Latin America. Children had shorter duration of illness, more lesions in the cephalic segment, smaller lesions, and lower number of ulcers. The occurrence of therapeutic failure was associated with younger age, shorter duration of the disease, greater number of lesions, and the bigger size of the largest lesion. Children were significantly more likely to fail treatment at 60 days but not at 90 days.

Cutaneous leishmaniasis is a disease that occurs predominantly in young male adults, and there was a predominance of males in all age ranges in the present study, but in particular in subjects with age ranging between 13 and 18 years. Multiple factors such as type of clothing, occupational exposure, and considering that farm workers are usually adult males may influence the occurrence of the disease in young males. However, in children and in adult population, both genders were expressed similarly. Others have already shown that children have usually shorter duration of illness and present with smaller lesions. ${ }^{7}$ This could be attributed to caring mothers taking their children to the clinic soon after noticing the lesion. We did not observe an increase in the number of cases in children with CL because in the same endemic area, it was $15 \%$ in children aged from 0 to 10 years for about 30 years ago, ${ }^{8}$ and in a retrospective study evaluating patients admitted in the Health Post of Corte de Pedra between 1988 and 2008, the frequency of children aged from 0 to 9 years was $14.3 \% .{ }^{7}$ In the present study, the frequency of children aged between 0 and 9 years with CL in this same Health Post was $14 \%$. This contradicts a recent review about epidemiologic and clinic features in American CL that has indicated that children have been more infected than has been documented in previous studies. ${ }^{28}$ We probably did not notice a difference because the time of the study was very short and we evaluated

TABLE 3

Independent predictors of therapeutic failure for cutaneous leishmaniasis in 571 patients treated with meglumine antimoniate, with age as a continuous variable

\begin{tabular}{|c|c|c|c|c|}
\hline \multirow[b]{2}{*}{ Variables } & \multicolumn{2}{|c|}{ Failure at 60 days } & \multicolumn{2}{|c|}{ Failure at 90 days } \\
\hline & OR (Cl 95\%) & $P$-value & OR (Cl 95\%) & $P$-value \\
\hline Age (years) & $0.983(0.973-0.994)$ & 0.001 & $0.983(0.974-0.992)$ & $<0.001$ \\
\hline Duration of the disease (days) & $0.995(0.988-1.002)$ & 0.130 & $0.987(0.979-0.995)$ & 0.001 \\
\hline Number of lesions & $1.223(0.991-1.510)$ & 0.061 & $1.176(1.005-1.376)$ & 0.043 \\
\hline Diameter of the biggest lesion $(\mathrm{mm})$ & $1.042(1.018-1.067)$ & 0.001 & $1.036(1.018-1.055)$ & $<0.001$ \\
\hline
\end{tabular}


the patients during only one period year. As in children, Leishmania transmission occurs peri- or intradomiciliarly, and because of small height of children, it is expected that this population have more lesions in the head as has been previously observed. ${ }^{7}$ It is known that lesion above the belt is associated with mucosal leishmaniasis. ${ }^{25}$ However, as mucosal lesions occur predominantly in the period of 2 years after $\mathrm{CL}$, the design of the current study did not allow us to evaluate if children have more mucosal leishmaniasis (ML). In the year 2016, there were 11 cases of ML, but all of them had CL for more than 1 year. However, the high frequency of lesions in the head of children indicates that these subjects should be systematically evaluated for mucosal disease independent of the presence of nasal symptoms. Because this was not performed in the current study, we cannot rule out that mucosal lesions were present and healed with the antimony therapy for CL. The greater size of the lesions in the adult population may be related to the longer illness duration in this group, but genotypic differences in isolates of $L$. braziliensis may also explain this finding. ${ }^{11}$ In addition, because children are smaller than adolescents and adults, smaller lesions in children may in fact occupy a larger percentage of body surface area. Because we do not have weight and height data for all patients, we could not evaluate this in detail.

A few previous studies have shown a high rate of failure to antimony therapy in children as compared with adults, and most of them were performed in patients infected with L. guyanensis, Leishmania panamensis, and Leishmania peruviana. ${ }^{21,25,27,29}$ A systematic review summarized the evidence on efficacy and safety for treatments in pediatric populations with CL. In general, the efficacy of the drug was lower in pediatric patients than in adults, regardless of treatment. ${ }^{30}$ The risk factors for failure to antimony therapy are well known and include short duration of illness, large lesions, atypical presentation of the disease, and multiple lesions. Among these, the occurrence of more than one lesion is considered the most important factor associated to failure. ${ }^{21,25,26,31,32}$ In the present study, the odds of therapeutic failure at day 90 increased by $17.6 \%$ for each additional lesion. We also showed that younger age, shorter duration of the disease, and larger diameter of the biggest lesions were also associated with therapeutic failure at day 90 .

Parasite factors may also influence the response to therapy. The cure rates with antimony are quite variable, ranging from $25 \%$ to $85 \% .^{33-35}$ It is known that CL caused by L. braziliensis presents a higher rate of failure to therapy in comparison with $C L$ due to $L$. panamensis or $L$. guyanensis. ${ }^{31,32,36}$ More recently, a great difference in the response to therapy has been observed in CL caused by L. braziliensis in different regions of Brazil. For instance, although in the south of the country the cure rate may be as high as $85 \%,{ }^{34,35}$ in our endemic area, in the northeast region of Brazil, the cure rate is lower than $55 \%$ in patients with ulcerated lesions ${ }^{19,37}$ and $25.8 \%$ in patients in the pre-ulcerative phase of the disease. ${ }^{33}$ It is known that $L$. braziliensis is polymorphic in our endemic area, and genotypic difference among isolates of the same species may influence the clinical presentation of the disease and the response to antimony therapy. ${ }^{11,38,39}$ Thus, it is possible that in addition to the previous observations of lower antimony levels in children than in adults, genotypic differences among isolates of $L$. braziliensis play a major role in response to therapy of CL caused by these species. However, we did not have sufficient DNA of the lesion from children to evaluate the genotypic characteristics of $L$. braziliensis in children.
This study analyzed a large number of children and adults with CL regarding clinical presentation of the disease and response to antimony therapy in an area of $L$. braziliensis transmission. We observed that children were more likely to present earlier and with lesions in the face than adults. Earlier diagnosis may be due to the fact that parents seek medical attention quickly for their children, whereas adults take longer time to seek medical care, mainly in rural areas because of work obligations besides other factors. The highest involvement of the area of the face in children may be related to their shorter stature, as the phlebotomine flies at very low altitude. Moreover, children were significantly more likely to fail antimony therapy at day 60 , even after adjusting for duration of the disease, number of lesions, and diameter of the biggest lesion. At day 90, even though children were more 1.25 times likely to fail treatment, the results were not statistically significant. There are significant disparities in the clinical presentation and response to therapy of CL between children and adults. We conclude that, unlike studies with other Leishmania species, we have not documented that children infected with L. brasiliensis presented greater failure to antimony treatment on day 60 after the initiation of treatment. It is possible that the polymorphism of $L$. braziliensis in our endemic area and the consequent greater therapeutic failure observed in this area have influenced this result. Physicians caring for children with CL should be aware that lesions may take longer to heal and remain alert for the possibility of higher odds of therapeutic failure in the children.

Received July 18, 2019. Accepted for publication December 26, 2019. Published online February 10, 2020.

Acknowledgment: We thank Cristiano Franco for their secretarial assistance.

Financial support: This work was funded by the National Institutes of Health (Grant U01 Al136032) and Coordenação de Aperfeiçoamento de Pessoal de Nível Superior (CAPES) and the Brazilian Research Council (CNPq).

Authors' addresses: Carvel Suprien and Paulo R. L. Machado, Immunology Service, Federal University of Bahia, Salvador, Brazil, E-mails: supriencarvel1@gmail.com and 19pmachado@gmail.com. Paulo N. Rocha, Programa de Pós-Graduação em Ciências da Saúde (PPGCS), Federal University of Bahia, Salvador, Brazil, E-mail: pnrocha001@yahoo.com.br. Marina Teixeira, Biology Department, University of Massachusetts Boston, Boston, MA, E-mail: marina.sa.teixeira@gmail.com. Lucas P. Carvalho and Edgar M. Carvalho, Immunology Service, Federal University of Bahia, Salvador, Brazil, and Laboratório de Pesquisas Clínicas (LAPEC), Instituto Gonçalo Moniz (IGM), Salvador, Brazil, E-mails: carvalholp76@ gmail.com and imuno@ufba.br. Luiz H. Guimarães, Medicina, Universidade Federal do Sul da Bahia, Bahia, Brazil, E-mail: luizhenriquesg@yahoo.com.br. Toby Bonvoisin, Academic Foundation Programme in Hull, The University of Sheffield, Sheffield, United Kingdom, E-mail: tobytb@gmail.com.

\section{REFERENCES}

1. Gontijo B, de Carvalho Mde L, 2003. American cutaneous leishmaniasis. Rev Soc Bras Med Trop 36: 71-80.

2. World Health Organization, 2016. Status of Endemicity of $C L$ Worldwide 2016. Available at: https://www.who.int/leishmaniasis/ burden/Status of endemicity of CL worldwide. Accessed June 2, 2019.

3. Ministry of Health, Brazil, 2017. Manual of Surveillance of American Cutaneous Leishmaniasis. Available at: http://bvsms.saude. 
gov.br/bvs/publicacoes/manual_vigilancia_leishmaniose tegumentar.pdf. Accessed June 2, 2019.

4. Grimaldi G, Porrozzi R, Friedrich K, Teva A, Marchevsky RS, Vieira F, Miekeley N, Paumgartten FJR, 2010. Comparative efficacies of two antimony regimens to treat Leishmania braziliensisinduced cutaneous leishmaniasis in rhesus macaques (Macaca mulatta). Antimicrob Agents Chemother 54: 502-505.

5. Alcaïs A, Abel L, David C, Torrez ME, Flandre P, Dedet JP, 1997. Evidence for a major gene controlling susceptibility to tegumentary leishmaniasis in a recently exposed Bolivian population. Am J Hum Genet 61: 968-979.

6. Weigle K, Saravia NG. 1996. Natural history, clinical evolution, and the host-parasite interaction in New World cutaneous leishmaniasis. Clin Dermatol 14: 433-450.

7. Jirmanus L, Glesby MJ, Guimarães LH, Lago E, Rosa ME, Machado PR, Carvalho EM, 2012. Epidemiological and clinical changes in American tegumentary leishmaniasis in an area of Leishmania (Viannia) braziliensis transmission over a 20-year period. Am J Trop Med Hyg 86: 426-433.

8. Jones TC et al., 1987. Epidemiology of American cutaneous leishmaniasis due to Leishmania braziliensis braziliensis. J Infect Dis 156: 73-83.

9. Morgan DJ, Guimaraes LH, Machado PRL, D'Oliveira A, Almeida RP, Lago EL, Faria DR, Tafuri WL, Dutra WO, Carvalho EM, 2007. Cutaneous leishmaniasis during pregnancy: exuberant lesions and potential fetal complications. Clin Infect Dis 45: 478-482.

10. Guimarães LH, Machado PRL, Lago EL, Morgan DJ, Schriefer A, Bacellar O, Carvalho EM, 2009. Atypical manifestations of tegumentary leishmaniasis in a transmission area of Leishmania braziliensis in the state of Bahia, Brazil. Trans $R$ Soc Trop Med Hyg 103: 712-715.

11. Guimarães LH et al., 2016. Atypical manifestations of cutaneous leishmaniasis in a region endemic for Leishmania braziliensis: clinical, immunological and parasitological aspects. PLoS Negl Trop Dis 10: e0005100.

12. Turetz ML, Machado PR, Ko Al, Alves F, Bittencourt A, Almeida RP, Mobashery N, Johnson WD, Carvalho EM, 2002. Disseminated leishmaniasis: a new and emerging form of leishmaniasis observed in northeastern Brazil. J Infect Dis 186: 1829-1834.

13. Machado PR, Rosa ME, Guimarães LH, Prates FV, Queiroz A, Schriefer A, Carvalho EM, 2015. Treatment of disseminated leishmaniasis with liposomal amphotericin B. Clin Infect Dis 61: 945-949.

14. World Health Organization, 2010. Leishmaniasis: The Global Trend. Available at: https://www.who.int/neglected diseases/ integrated media leishmaniasis. Accessed June 2, 2019.

15. Schubach $A$ et al., 2001. Leishmanial antigens in the diagnosis of active lesions and ancient scars of American tegumentary leishmaniasis patients. Mem Inst Oswaldo Cruz 96: 987-996.

16. Prates FV, Dourado ME, Silva SC, Schriefer A, Guimarães LH, Brito MD, Almeida J, Carvalho EM, Machado PR, 2017. Fluconazole in the treatment of cutaneous leishmaniasis caused by Leishmania braziliensis: a randomized controlled trial. Clin Infect Dis 64: 67-71.

17. Correia D, Macêdo VO, Carvalho EM, Barral A, Magalhães AV, de Abreu MV, Orge ML, Marsden P, 1996. Comparative study of meglumine antimoniate, pentamidine isethionate and aminosidine sulfate in the treatment of primary skin lesions caused by Leishmania (Viannia) braziliensis. Rev Soc Bras Med Trop 29: 447-453.

18. Sampaio RN, Sampaio JH, Marsden PD, 1985. Pentavalent antimonial treatment in mucosal leishmaniasis. Lancet 1: 1097.

19. Machado PR, Ampuero J, Guimarães LH, Villasboas L, Rocha AT, Schriefer A, Sousa RS, Talhari A, Penna G, Carvalho EM, 2010. Miltefosine in the treatment of cutaneous leishmaniasis caused by Leishmania braziliensis in Brazil: a randomized and controlled trial. PLoS Negl Trop Dis 4: e912.

20. Brito G, Dourado M, Polari L, Celestino D, Carvalho LP, Queiroz A, Carvalho EM, Machado PRL, Passos S, 2014. Clinical and immunological outcome in cutaneous leishmaniasis patients treated with pentoxifylline. Am J Trop Med Hyg 90: 617-620.

21. Palacios R, Osorio LE, Grajalew LF, Ochoa MT, 2001. Treatment failure in children in a randomized clinical trial with 10 and 20 days of meglumine antimonate for cutaneous leishmaniasis due to Leishmania viannia species. Am J Trop Med Hyg 64: 187-193.

22. Castro MD, Gomez MA, Kip AE, Cossio A, Ortiz E, Navas A, Dorlo TP, Saravia NG, 2017. Pharmacokinetics of miltefosine in children and adults with cutaneous leishmaniasis. Antimicrob Agents Chemother 61: e02198-16.

23. Cruz A, Rainey PM, Herwaldt BL, Stagni G, Palacios R, Trujillo R, Saravia NG, 2007. Pharmacokinetics of antimony in children treated for leishmaniasis with meglumine antimoniate. $J$ Infect Dis 19: 602-608.

24. Reed SG, Badaró R, Masur H, Carvalho EM, Lorenco R, Lisboa A, Teixeira R, Johnson WD Jr., Jones TC, 1986. Selection of a skin test antigen for American visceral leishmaniasis. Am J Trop Med Hyg 35: 79-85.

25. Llanos-Cuentas EA, Cuba CC, Barreto AC, Marsden PD, 1984. Clinical characteristics of human Leishmania braziliensis braziliensis infections. Trans R Soc Trop Med Hyg 78: 845-846.

26. O'Neal SE, Guimarães LH, Machado PR, Alcântara L, Morgan DJ, Passos S, Glesby MJ, Carvalho EM, 2007. Influence of helminth infections on the clinical course of and immune response to Leishmania braziliensis cutaneous leishmaniasis. J Infect Dis 195: 142-148.

27. Valencia C, Arévalo J, Dujardin JC, Llanos-Cuentas A, Chappuis F, Zimic M, 2012. Prediction score for antimony treatment failure in patients with ulcerative leishmaniasis lesions. PLOS Negl Trop Dis 6: e1656.

28. Paniz-Mondolfi AE, Talhari C, García Bustos MF, Rosales T, Villamil-Gomez WE, Marquez M, Rodriguez-Morales AJ, 2017. American cutaneous leishmaniasis in infancy and childhood. Inter J Dermatol 56: 1328-1341.

29. Romero GA, Guerra MV, Paes MG, Macêdo VO, 2001. Comparison of cutaneous leishmaniasis due to Leishmania (Viannia) braziliensis and L. N.) guyanensis in Brazil: therapeutic response to meglumine antimoniate. Am J Trop Med Hyg 65: 456-465.

30. Uribe-Restrepo A, Cossio A, Desai MM, Dávalos D, Castro MDM, 2018. Interventions to treat cutaneous leishmaniasis in children: a systematic review. PLoS Negl Trop Dis 12: e0006986.

31. Arevalo J et al., 2007. Influence of Leishmania (viannia) species on the response to antimonial treatment in patients with American tegumentary leishmaniasis. J Infect Dis 195: 1846-1851.

32. Llanos-Cuentas A et al., 2008. Clinical and parasite species risk factors for pentavalent antimonial treatment failure in cutaneous leishmaniasis in Peru. Clin Infect Dis 46: 223-231.

33. Unger A, O'Neal S, Machado PRL, Guimarães LH, Morgan DJ, Schriefer A, Bacellar O, Glesby MJ, Carvalho EM, 2009. Association of treatment of American cutaneous leishmaniasis prior to ulcer development with high rate of failure in northeastern Brazil. Am J Trop Med Hyg 80: 574-579.

34. Vasconcellos Ede $C$ et al., 2012. Intralesional meglumine antimoniate for treatment of cutaneous leishmaniasis patients with contraindication to systemic therapy from Rio de Janeiro (2000 to 2006). Am J Trop Med Hyg 87: 257-260.

35. Saheki MN et al., 2017. Low versus high dose of antimony for American cutaneous leishmaniasis: a randomized controlled blind non-inferiority trial in Rio de Janeiro, Brazil. PLoS One 12: e0178592.

36. Reveiz L, Maia-Elkhoury ANS, Nicholls RS, Romero GAS, Yadon ZE, 2013. Interventions for American cutaneous and mucocutaneous leishmaniasis: a systematic review update. PLOS One 8: e61843.

37. Brito G, Dourado M, Guimarães LH, Meireles E, Schriefer A, de Carvalho EM, Machado PRL, 2017. Oral pentoxifylline associated with pentavalent antimony: a randomized trial for cutaneous leishmaniasis. Am J Trop Med Hyg 96: 1155-1159.

38. Queiroz A, Sousa R, Heine C, Cardoso M, Guimarães LH, Machado PRL, Carvalho EM, Riley LW, Wilson ME, Schriefer A, 2012. Association between an emerging disseminated form of leishmaniasis and Leishmania (Viannia) braziliensis strain polymorphisms. J Clin Microbiol 50: 4028-4034.

39. Silva SC, Guimarães LH, Silva JA, Magalhães V, Medina L, Queiroz A, Machado PRL, Schriefer A, 2018. Molecular epidemiology and in vitro evidence suggest that Leishmania braziliensis strain helps determine antimony response among American tegumenary leishmaniasis patients. Acta Trop 178: 34-39. 